\title{
A Study on Tourism Education Research Progress in China from 1994 to 2013
}

\author{
Xinyu Wu \& Wei Zhang \\ Economic and Management School of Wuhan University, Wuhan, China
}

\begin{abstract}
With the prosperity of tourism industry and the development of tourism education after China's reform and opening policy, tourism education research has gained great attention by scholars with enormous literature. This thesis, based on the methods of bibliometrics and content analysis, studies on the progress of tourism education research from 1990 to 2009 in China in-light of existing literature published on CNKI net. It points out hot issues commonly concerned, consensus and main controversy in tourism education research for the past twenty years. It makes a conclusion that practical investigation and multi-research methods should be paid more attention in future tourism education research.
\end{abstract}

KEYWORD: Tourism Education; Research Progress; Bibliometric Analysis; Content Analysis

\section{INTRODUCTION}

\subsection{Rearch background}

With the trend of globalization in the 21 st century and the promoting of Beijing Olympic Games in 2008 and Shanghai World Expo in 2010, both international and domestic tourism have gained rapid growth accompanying with the flourish of tourism education in China. According the statistics of National Tourism Yearbook and China National Tourism Administration, there are 252 tourism colleges (universities) with 73,586 students, while 943 secondary vocational schools with 254,352 students in 2000. While, by the end of 2012, it has soared to 1097 colleges (universities) with 576 thousand students, while the amounts of secondary vocational schools has grown to 1139 with 497 thousand students for which shows rapid development and change of tourism education in China in the 21 st century. Based on the methods of bibliometric and content analysis, this thesis mainly focuses on the literature of tourism education research on CNKI from 1994 to 2013, in order to analyze hot topics of tourism education for the past 20 years and explore its future trends.

\subsection{Research Methods}

The methods of bibliometric and content analysis started from the last mid-century, then their unique research methodologies were formed. For bibliometrics, mathematical statistics is mainly used to attain quantitative relations among literature and information, which is quantitative -based and can be applied to all subjects. On the other hand, the method of content analysis mainly uses symbols analysis to deal with various contents including text, images, audio, video and other information in order to explore qualitative and quantitative relationship between groups, which is theme-based and has been widely applied to social science disciplines. From a quantitative point of view, bibliometric analysis indirectly reflects the correlation among contents, while content analysis not only focuses on the external features of contents but also the specific contents. So it can be seen that bibliometric and content analysis methods emphases differently and they can make well up for the shortcomings of qualitative and quantitative research methods.

In recent years, the researches on the methodology and application of bibliometrics and content analysis are relatively small in China, only by Wang Yuefen (2009), Zheng Wenhui (2006), Ye Ying (2005). The achievements mainly appeared in recent years. Zhang Wei (2009) used bibliometric methods to analyze the research progress of global tourism. The method of content analysis was used in 7 theses, such as Fan Xiangli (2010), Xiao Liang (2009), etc. So, it can be seen that the application of these two methods is a truly new exploration and innovation in tourism academia research. 


\subsection{Research steps}

\subsubsection{Data Acquisition}

In this thesis, Tourism education was used as key words to retrieve literature from 1994 to 2013 on CNKI database and downloaded their title, author, keywords, abstract and full text on July 15, 2014. 2127 documents are obtained in China Academic Journal, 3 documents in China Doctor Dissertations Full-text database and 189 documents in China Excellent Master Dissertations Full-text database.

\subsubsection{Data Cleaning}

By deleting non-sense text, filling or removing the missing text and merging duplicated text among a large number of collected data, data cleaning is a key step before formal analysis, aiming to improve analysis quality and ensure the authenticity and reliability of results. It is difficult for computer to identify these non-sense texts, so it has to be finished by manual operation. In this thesis, manual browsing and observation method are mainly used, judging by keywords and title and directly removing the nonsense text, such as announcements, reports, news and profile. Next step is to merge duplicate text. The same or similar syntax records in the database can represent the same record in the real world. So it merges the same paper written by the same author in different journals and the duplicate records of same author, same title and same journal in this study. For repetitive texts, traditional methods of sorting, combining and clustering are used to identify duplicate records. Through these steps above, 244 documents are removed and merged and 1883 documents are finally used as statistical sample for this study.

\section{BIBLIOMETRIC ANALYSIS AND RESULTS}

\subsection{Statistical Analysis of Annual Basic Information}

'Tourism Education' is used as the Subject to retrieve documents and conduct annual statistics from 1994 to 2013. The annual frequency distribution is shown in Table 1. From the time point of view, it has a significant growth for tourism education literature since 1996, while a slight drop in 2000 and 2001, from then, there is a rapid increase until 2013. Clearly, the average growth from 2004 to 2013 is 6 times than its average growth from 1994 to 2003, which shows the academic progress of tourism education research is followed by the fast growth of tourism education development.
Table 1. Annual frequency distribution from 1994 to 2013.

\begin{tabular}{|c|c|c|c|}
\hline year & frequency & year & frequency \\
\hline 2013 & 196 & 2003 & 62 \\
\hline 2012 & 213 & 2002 & 31 \\
\hline 2011 & 210 & 2001 & 30 \\
\hline 2010 & 194 & 2000 & 25 \\
\hline 2009 & 183 & 1999 & 39 \\
\hline 2008 & 182 & 1998 & 33 \\
\hline 2007 & 135 & 1997 & 27 \\
\hline 2006 & 109 & 1996 & 17 \\
\hline 2005 & 89 & 1995 & 4 \\
\hline 2004 & 96 & 1994 & 8 \\
\hline
\end{tabular}

\subsection{Statistical Analysis of Source Publications Distribution}

It can be found that there are 28 kinds of journal respectively publishing more than 10 papers as shown in Table 2. Tourism Tribune is a key representative journal in the field of tourism researches and it publishes special journal on tourism education research each year. Thus it has published 132 papers on tourism education research. Followed by Tourism Forum, it reaches 83 papers. Meanwhile, there are 94 master thesis on tourism education in Liaoning Normal University from 2000 to 2013, reflecting its Normal discipline characteristic and also illustrating the growth of graduate enrollment and expansion of higher tourism education.

Table 2. The Top Ten Amounts of Source Journals from 1994 to 2013

\begin{tabular}{|c|l|c|}
\hline Rank & Journal & Amounts \\
\hline 1 & Tourism Tribune & 132 \\
\hline 2 & Tourism Forum & 83 \\
\hline 3 & Tourism Scan & 61 \\
\hline 4 & Science and Technology Information & 38 \\
\hline 5 & Toursim Science & 35 \\
\hline 6 & Commercial Modernization & 32 \\
\hline 7 & \begin{tabular}{l} 
Journal Beijing International Studies \\
\hline 8
\end{tabular} & 30 \\
\hline 9 & Eninersity Adult Education & 21 \\
\hline 10 & Vocational Education Forum & 20 \\
\hline
\end{tabular}

\subsection{Statistical Analysis of Fund Support}

According to statistics of Zhao Peng and Yu Jifeng in 2007, domestic dissertation supported by tourism education research fund appeared in 1997 and it increased year by year. Because of different searchcaliber, this thesis can not directly cite this data. So it 
recounts according to retrieve data and the result is shown in Table 3. It can be found that there are 70 dissertations supported by fund from 1994 to 2013, including 17 dissertations supported by National Natural Science and Social Science Funds, 53 dissertations supported by Ministry of Education and Provincial Fund. It should be paid attention that some dissertations supported by multi-funds, such as supported both by National and Provincial Funds, so it only counts the highest level of funds in order to avoid duplicate statistics. The change frequency of annual funds can be directly observed in Figure 2 . Although there is a time lag between published dissertations and funds application, it shows that governments and research institutions greatly emphasizes and supports on tourism education research in recent years.

Table 3. Annual Statistics of Fund Supported Dissertations from 1994 to 2013.

\begin{tabular}{|c|c|c|c|}
\hline year & frequency & year & frequency \\
\hline 2013 & 5 & 2003 & - \\
\hline 2012 & 14 & 2002 & - \\
\hline 2011 & 9 & 2001 & - \\
\hline 2010 & 8 & 2000 & - \\
\hline 2009 & 5 & 1999 & - \\
\hline 2008 & 3 & 1998 & - \\
\hline 2007 & 4 & 1997 & 1 \\
\hline 2006 & 6 & 1996 & - \\
\hline 2005 & 11 & 1995 & - \\
\hline 2004 & 25 & 1994 & - \\
\hline
\end{tabular}

\section{CONTENT ANALYSIS AND RESULTS}

\subsection{Keywords and Hot Issues Analysis}

Key words are those meaningful, important and critical words appear in title, abstract, chapter, which reveal and describe the thematic content and reflect core results. Hence, the statistical frequency analysis on keywords is of great value. In addition to the keyword of 'tourism education', this thesis conducts a frequency analysis on the others keywords on tourism education research, as shown in Table 4.

It can be found that the $f$ average frequency of words is 38 times. By removing the words without actual meanings, such as countermeasures, problems, thinking, research, there are still 19 highfrequency words above average level, that is, development, profession, occupation, vocation, vocational education, teaching, China, model, talent, reformation, status-quo, innovation, practice, quality, college, students, undergraduate, courses, which reflects the research on tourism education focusing on the problems and development of tourism education in China, such as higher tourism education, vocational education, higher vocational education, teaching, courses, innovation, talents cultivation, cultivation and its reforming measures. Meanwhile, it shows that the glaring contradiction between the practice and research of tourism education has been recognized by scholars in China in the past 20 years and they try to come up with new solutions.

Table 4. Annual Statistics of Fund Supported Dissertations from 1994 to 2013.

\begin{tabular}{|l|c|l|c|}
\hline Keywords & Frequency & Keywords & Frequency \\
\hline $\begin{array}{l}\text { Higher } \\
\text { education }\end{array}$ & 295 & Students & 43 \\
\hline Development & 191 & Under-graduate & 43 \\
\hline Major & 176 & Course & 41 \\
\hline Occupation & 166 & Pre-explore & 40 \\
\hline Research & 163 & International & 37 \\
\hline $\begin{array}{l}\text { Higher } \\
\text { vocational } \\
\text { education }\end{array}$ & 130 & University & 36 \\
\hline $\begin{array}{l}\text { Vocational } \\
\text { education }\end{array}$ & 116 & Cooperation & 31 \\
\hline Teaching & 110 & Education model & 31 \\
\hline China & 104 & Province & 29 \\
\hline Model & 103 & Explore & 29 \\
\hline Thinking & 84 & Environment & 26 \\
\hline $\begin{array}{l}\text { Counter- } \\
\text { measures }\end{array}$ & 79 & Training model & 25 \\
\hline Talents & 71 & Teaching model & 22 \\
\hline Reformation & 68 & Feature & 19 \\
\hline Issue & 65 & Schools- enterprises & 19 \\
\hline Status-quo & 51 & Compare & 17 \\
\hline Innovation & 50 & Strategy & $\begin{array}{l}\text { Environmental } \\
\text { education }\end{array}$ \\
\hline Practice & 48 & Curriculum system & 19 \\
\hline Cultivation & 48 & Quality & 19 \\
\hline Colleges & 45 & & 19 \\
\hline
\end{tabular}

Wang Jinwei (2008) divided tourism education research into 6 parts, including tourism education development and discipline construction, tourism educational functions and talents cultivation, education system structure, tourism courses and teaching books, tourism education and teaching and tourism education management. Zhao Peng (2007) found that tourism education development, local tourism education, talents cultivation and professional education were the hot issues in tourism education research based on the analysis of top four journals. In this thesis, it analyzes the content correlations among keywords in the sampled title by 
frequency statistics and the results can be seen in Table 4.

\subsection{Research Methods Analysis}

Zhao Peng (2007) believes that $85 \%$ of researches on tourism education are shallow and simple. Moreover, by high-frequency words analysis, it can be seen that a large number of researches only describe the status, problems and countermeasures of tourism education with duplicate contents and single research method. It shows the weakness of tourism education research in China, besides, it has revealed the common problems existing in domestic tourism academic circles, that is, scholars rely on personal experience and judgments to insight into an issue and gives some opinions. It is hard for them to conduct deep quantitative research by experiments, questionnaire or content analysis method.

\section{CONCLUSION}

According to the literature analysis of tourism education research in China from 1994 to 2013, conclusions are as following. Firstly, there has been a rapid development for tourism education research since 2000 in China. Besides, tourism education research has become an important part of tourism research reflected by the amounts, level and results of tourism education research projects.

Secondly, the relationship between the hot spots of research and the practice of tourism education is closer. Such as, the problems concerning discipline construction, cultivation model, vocational education and curriculum reformation faced by tourism education in practice is also the key issues explored by tourism education research. Meanwhile, the requirement on tourism talents is higher and higher with the development of tourism industry. So it is imperative that tourism education should make appropriate adjustments.

Thirdly, qualitative analysis is still the major method applied by scholars in China and empirical and quantitative analysis methods are highly expected. Finally, it is clear that relatively independent research team of tourism education has began to form. In addition to comprehensive researchers who pay great attention to tourism education issues, independent research team of tourism education is in sight. Some universities have begun to set up Master of Tourism Education, such as Northeast Normal University, Liaoning Normal University and so on.

\section{REFERENCES}

[1] Fan Xiangli \& Zheng Xiangmin. 2010. The application of content analysis in tourism security studies. Journal Beijing International Studies University (3): 37-44.

[2] Wang Jinwei \& Hu Tianshu, Su caiyun. 2008. Progress and Commentary on Tourism Education for the past thirty years. Journal of Shanxi Finance and Economics University (Education Edition): 38-42.

[3] Wang Min \& Song Haiyan. 2008. Review and Reflection on Tourism Education Research Methods - the application of phenomenological method. Higher Education Research (6): $18-2$.

[4] Xiao Liang \& Zhao Liming. 2009. Internet spreading of tourism destinations image inTaiwan - Based on content analysis of websites in Taiwan and Mainland. Tourism Tribune (3): 75-81.

[5] Zhang Wei, Zhong Sheng \& Zhang Xiaoyan. 2009. The progress on Global Tourism research from 1998 to 2007 Based on Bibliometric Analysis of SCIES, SCI and A \& HCI Database. Tourism Tribune (12): 78-83.

[6] Zhao, Peng \& Yu Jifeng. 2007. Statistical Analysis on the Development of Domestic Tourism Education Research from the Chinese Journals. Tourism Tribune (9): 75-79. 